\title{
SENTIDO E VERDADE: HEIDEGGER E "A NOITE ABSOLUTA"
}

Róbson Ramos dos Reis

SÍNTESE - Neste artigo o autor aplica a interpretação social-institucional da constituição ontológica na análise da teoria heideggeriana acerca da relatividade da verdade em relação ao ser do Dasein. A presente reconstrução é desenvolvida por meio da apresentação do assim chamado carátér de verdade do ser, bem como da interpretação ontológico existencial da gênese da ontologia da presentidade (Vorhandenheit) a partir da disponibilidade (Zuhandenheit). No asserir localiza-se a prática recognitiva capaz de instituir a categoria da pura subsistência, na qual reside a condição existencial da possibilidade da verdade. Essa dependência existencial da verdade permite o reconhecimento da condição da total falta de descobrimento ôntico: a ausência completa do Dasein, que Heidegger chamou de 'noite absoluta'.

PALAVRAS-CHAVE - Heidegger. Verdade. Asserção.
ABSTRACT - In this paper the author applies the social-institutional interpretation of ontological constitution for the analysis of the heideggerian theory about the relativity of truth to Dasein's Being. The present reconstrution is developed by the exposition of the so called truth's character of Being, and by the ontological-existential interpretation of the genesis of Vorhandenheit from Zuhandenheit. Assertion is the specific social-recognitive performance that can institute the pure subsistence's category, which contains the existential condition of possibility of truth. This existential dependence of truth makes possible the recognition of a condition of total lack of ontic discovery: the complete absence of Dasein, that Heidegger called "absolute night". KEY WORDS - Heidegger. Truth. Assertion.

\section{1 "A noite absoluta"}

Erro metodológico: essa é a acusação dirigida a quem pretende retomar o problema do ser, escrevia Heidegger no segundo parágrafo de Ser e Tempo, referindo-se à objeção derivada da universalidade, indefinibilidade e trivialidade do conceito ser. ${ }^{1}$ Passados alguns anos, uma censura similar the é dirigida. Dois anos depois da publicação do livro, e dois anos antes de Carnap, Gilbert Ryle já indica-

Professor no Departamento de Filosofia da Universidade Federal de Santa Maria, UFSM.

As seguintes abreviaturas serão utilizadas para a referência aos escritos de Heidegger: $S Z$ - Sein und Zeit; GA 1 - Frühe Schriften; GA 24 - Die Grundprobleme der Phänomenologie; GA 21 - Logik die Frage nach der Wahrheit; GA 26 - Metaphysische Anfansgründe de Logik im Ausgang von Leibniz GA 27 - Einleitung in die Philosophie.

\begin{tabular}{|l|l|l|l|l|l|}
\hline VERITAS & Porto Alegre & v. 45 & n. 2 & Junho 2000 & p. 231-248 \\
\hline
\end{tabular}


va os perigos filosóficos derivados de interpolações metafísicas não identificadas pelo método fenomenológico (Ryle, 1929, p. 61). Não é necessário percorrer novamente as conhecidas argüições críticas voltadas para os fundamentos metodológi$\cos$ da ontologia fundamental e dos escritos de Heidegger como um todo. Basta lembrar que ainda recentemente encontramos posições dessa natureza, e até mesmo em destacados filósofos oriundos do colégio fenomenológico, como KarlOtto Apel e Ernst Tugendhat, encontramos objeções internas, mas nem por isso dissociadas da objeção metodológica de fundo (Tugendhat, 1992; Apel, 1991). Em todos esses casos a lição parece ser a seguinte: o modo de filosofar presente na obra de Heidegger é um exemplo da incapacidade de seguir regras mínimas de controlabilidade metodológica.

Um dos temas que tem servido como documento dessa suposta falta de rigor localiza-se na muito citada passagem do final do parágrafo 44 de Ser e Tempo, quando a dependência da verdade ou falsidade de enunciados em relação ao existente humano é posta nos seguintes termos:

"Somente 'há' verdade enquanto e na medida em que o Dasein é. O ente somente está descoberto e aberto quando e enquanto o Dasein é. As leis de Newton, o princípio de contradição e em geral toda verdade somente são verdadeiros enquanto o $\mathrm{Da}$ sein é. Antes que houvesse o Dasein, e depois que não houver mais o Dasein, não havia e não haverá nenhuma verdade, porque ela não pode ser no modo da abertura, do descobrimento e da condição de estar descoberto. Antes que as leis de Newton fossem descobertas elas não eram 'verdadeiras' [...]". (226)

Note-se que a afirmação toma leis da ciência natural, um princípio da lógica clássica, e finalmente estende a sua alegação para qualquer tipo de verdade. No texto referido como a terceira seção não publicada de Ser e Tempo, Heidegger ainda inclui nessa mesma afirmação enunciados aritméticos típicos, englobando assim também as ciências formais em sua posição (GS 24, s. 315). Guardadas as diferenças, é esta mesma doutrina que é apresentada em relação às afirmações sobre a existência independente de entes, na seguinte passagem do § 43:

“Certamente, 'há' ser tão somente enquanto o Dasein é, quer dizer, enquanto a possibilidade ôntica da compreensão de ser é. Se o Dasein não existe, tampouco a independência 'é', e tampouco o em-si 'é'. Nada disso é, pois, compreensível nem incompreensivel. $\mathrm{E}$ assim tampouco o ente intramundano pode ser descoberto ou ficar no ocultamento. Em tal caso não se pode dizer que o ente seja ou não seja. Agora, enquanto a compreensão de ser é, então podemos dizer que o ente ainda seguirá sendo." (212)

Temos aqui uma afirmação estruturalmente análoga, pois está em questão a verdade de enunciados acerca da existência de entes. Neste caso, Heidegger estaria afirmando um idealismo robusto, pois a ausência do Dasein representaria a impossibilidade de afirmar ou negar a existência de entes.

De início, uma primeira observação crítica diria que nessas passagens fica evidente a desconsideração da especificidade dos tipos lógicos a que pertencem cada um dos exemplos citados. Conseqüentemente, tampouco as suas condições 
de verdade teriam sido reconhecidas em sua propriedade, com as implicações epistemológicas e filosóficas derivadas deste déficit reflexivo. Entretanto, em ambas as passagens estaria patente o mais simples dos erros, uma confusão que está na base dos mais diferentes tipos de psicologismos e falácias genéticas que apareceram na história da filosofia. Afirmar que enunciados verdadeiros têm a sua verdade dependente do existente humano seria um claro exemplo de psicologismo, e, em última instância, de relativismo cético, que um aprendizado lógico elementar teria evitado sem dificuldades, distinguindo a verdade e 0 reconhecimento da verdade de um enunciado.

Ora, a diferença entre o pensamento capaz de ser verdadeiro ou falso e os atos de conceber e expressar tal pensamento é uma imagem inaugural nos fundamentos da filosofia da Lógica. Numa formulação lingüística costumamos distinguir entre a proposição capaz de portar a verdade ou a falsidade e a ação de enunciá-la ou asseri-la. De um lado temos, portanto, o pensamento, a proposição, o sentido, o conteúdo sentencial, e de outro as ações referentes à concepção de tal pensamento, ao seu proferimento lingüístico, e à asserção de sua verdade. Com base nessa distinção ainda reconhecemos a diferença entre o ser verdadeiro ou falso de um conteúdo sentencial e a sua confirmação ou reconhecimento como tal. Deste modo, há uma trivialidade que reside na distinção entre a confirmação, o reconhecimento, a concepção e a asserção da verdade de um conteúdo proposicional, e este mesmo conteúdo, cuja verdade ou falsidade são independentes de que sejam reconhecidas, confirmadas e asseridas por alguém.

Martin Heidegger conhecia e compartilhava essa doutrina. Já no seu elogio a Frege (GA 21, s. 20), e no exame crítico da doutrina do juízo no psicologismo (GA 1, ss. 59-188), estava evidente o reconhecimento dessa distinção como sendo básica para a determinação dos fundamentos da Lógica e de seu campo temático. Não obstante, o amadurecimento da fenomenologia hermenêutica aparentemente o conduz para uma posição distante, culminando ${ }^{2}$ na tese exemplar da ontologia fundamental, que estabelece uma dependência última, relativa ao Dasein, de toda relação de fundação. Essa tese é presente em todo seu poder expressivo nas passagens acima citadas, em que sua generalidade alcança princípios da Lógica, enunciados de igualdade da Aritmética, enunciados generalizados da ciência natural, sentenças existenciais, e qualquer sentença veritativa da linguagem comumbe um ponto de vista histórico, sabemos que o pano de fundo dessa doutrina encontra-se numa discussão crítica com os pressupostos ontológicos da instauração do domínio próprio da Lógica. Mais precisamente, Heidegger está se enfrentando com a aceitação implícita de uma ontologia nos fundamentos da Lógica, a saber, todas as variantes da doutrina da validade originada em Hermann Lotze. ${ }^{3}$ A

2 Já antevista no escrito sobre a doutrina do significado e das categorias em Duns Scotus (GA 1, ss. 4-5-6), pois à Lógica era posta a exigência de buscar os seus fundamentos para além de si mesma, no dominio da metafísica.

3 Com a Gesamtausgabe foi confirmada a tese de Gottfried Gabriel, segundo a qual não se deveria estudar Heidegger antes de estudar Lotze (1990, p. 465-467). 
discriminação de um sentido (pensamento, ou proposição), cuja verdade seria independente de sua asserção ou reconhecimento, é tributária de uma ontologia que regionaliza domínios de objetos, afirmando que o modo de ser próprio a estes elementos não é nem o psíquico, nem o físico, mas o do valer: a validade (Geltung). De acordo com Heidegger, o problema não está em fazer tal distinção, mas em não reconhecer a sua natureza ontológica e a necessidade de sua justificação. Curiosamente, o cerne da doutrina heideggeriana foi apresentado a partir de uma metáfora acerca da condição extrema, na qual não haveria mais o Dasein como possibilidade de toda verdade. Em uma passagem muito similar às duas acima citadas, ${ }^{4}$ e referindo-se a Lotze e sua herança (para a qual sentenças verdadeiras valem independentemente de que alguém as reconheça), Heidegger afirma que as sentenças não são o 'lugar' originário da verdade, e que por isso a validade não é o modo originário de ser da verdade. Referindo-se explicitamente a Hegel, Heidegger nomeia a condição de ausência de toda a verdade pela expressão 'noite absoluta', dizendo:

"Somente porque a verdade qual abertura (desvelamento) do Dasein existe no modo de ser deste ente, ou seja, constitui simultaneamente a existência, somente por isso as sentenças verdadeiras podem, por seu turno, valer. Falar de sentenças verdadeiras e de validades em si é desprovido de sentido e superficial. Se nenhum Dasein existe também não há nenhuma verdade, mas muito menos inverdade. Então é a noite absoluta, na qual, como diz Hegel, todos os gatos são pretos, ou então, visto exatamente, nem mesmo isto é possivel." (GA 27, s. 153)

Como já foi dito, tal posição foi objeto de inúmeras críticas, que variam desde a acusação de antropologismo, psicologismo e contradição performativa, até a de relativismo cético. ${ }^{5}$ Guardadas as diferenças, se argumentaria que essa doutrina confunde as condições de apreensão e asseribilidade de um conteúdo portador da verdade com as condições da verdade do próprio conteúdo. Ou seja, devemos distinguir o pensamento, proposição, ou sentido capaz de ser verdadeiro ou falso, e os atos e elementos que condicionam o seu reconhecimento ou asserção. Mesmo uma leitura mais fiel ao texto de Heidegger, no qual se afirma que sem o $\mathrm{Da}$ sein não é possível nem verdade nem falsidade, mesmo uma tal leitura não se privaria da crítica de que essa posição apenas acentua uma trivialidade. A tão repercutida tese da dependência em relação ao Dasein seria precisamente a indicação dessa distinção: condições de asseribilidade e o conteúdo asserido. Afirmar que sem o Dasein não podemos dizer que algum conteúdo sentencial é verdadeiro ou falso apenas significa que sem as condições de asseribilidade não há conteúdo asserido, conseqüentemente, não faz sentido dizer que há verdade ou falsidade.

A acusação de que a posição heideggeriana apenas acentuaria uma trivialidade não representa propriamente uma crítica, dado que a fenomenologia é tomada como a investigação sobre as trivialidades filosóficas ("os juízos secretos da razão

Na Lição de inverno de 1928/29, Introdução à Filosofia (GA 27).

Dois exemplos recentes são Apel (1991) e Puntel (1997). 
comum", ver SZ, 4 e GA 21, s. 197). Não obstante, há mais do que uma tematização de trivialidades, mas estamos diante de considerações que apontam para uma construção positiva em torno do problema das condições da verdade enunciativa. Do mesmo modo como Heidegger afirmava que toda refutação do ceticismo (através da apresentação do seu suposto caráter auto-contraditório) não conseguia reconhecer que o problema do ceticismo é parte de uma investigação sobre as condições da verdade em geral (GA 21, s. 22), do mesmo modo, a tese da possibilidade da noite absoluta - a dependência de toda verdade proposicional em relação ao Dasein - deve ser tomada como a indicação formal (formale Anzeige) de uma doutrina da verdade e das condições da verdade. No seu ponto de chegada essa abordagem exigirá que se problematize a trivialidade que reside no asserir um conteúdo proposicional. Nela há mais do que a distinção reconhecida: em tal obviedade está presente o núcleo das condições ontológicas da verdade proposicional.

No que se segue examinarei a objeção de que a doutrina dos fundamentos ontológico-existenciais da verdade repousaria numa confusão como a acima descrita, argumentando que ela é insustentável, e sendo possível apenas a partir do desconhecimento do inteiro programa fenomenológico-hermenêutico esboçado em Ser e tempo. Esse desconhecimento, por outro lado, fecha os olhos para um tratamento possivel deste clássico problema da filosofia da lógica, que, em última instância representa todo um programa de investigações construtivas sobre os temas da teoria do conhecimento, da filosofia da linguagem, e da metafísica da mente. Tal programa perfaz uma abordagem que não se pauta mais pela constelação do ceticismo e sua refutação, e em verdade exige um redimensionamento nas prioridades temáticas da filosofia.

Guardando a especificidade de uma lógica transcendental radicalizada hermeneuticamente, o que está em jogo não é a confusão entre o ser verdadeiro e o tomar por verdadeiro, mas sim a abertura de uma nova perspectiva de colocação do problema da possibilidade da verdade. Essas condições não são apenas lógicosemânticas, mas incidem no nível propriamente ontológico das condições para que um enunciado possa estar na alternativa da verdade ou falsidade. O problema central nesse nível de consideração deve ser bem entendido, pois a formulação heideggeriana distingue-se da formulação clássica da filosofia primeira, isto é, como a determinação das propriedades e leis que valem dos entes enquanto entes, ou como uma teoria formal dos objetos.

Abordaremos esse tópico em três partes. A primeira busca determinar a relação entre o conceito de verdade e o problema ontológico em Ser e Tempo, por meio de uma análise daquilo que Heidegger chamava de o caráter de verdade do ser. $^{6}$ A seguir, apresentaremos os pontos centrais de uma reconstrução social institucional do fenômeno do enunciado descritivo, permitindo a identificação das pressuposições ontológicas para a possibilidade da verdade. Por fim, faremos al-

Essa formulação está no livro Problemas fundamentais da fenomenologia (GA 24), que era tomado por Heidegger como a terceira seção da primeira parte de Ser e tempo. 
gumas considerações gerais, acerca do alcance de tal posição, o que permitirá, inclusive, tangenciar a natureza de uma problematização do ser e do pensamento da verdade do ser, para usar a expressão do Heidegger tardio.

\section{O caráter de verdade do ser}

Quanto ao primeiro ponto, a noção de ser refere-se aquilo que determina o ente como ente, isto é, aquilo que já sempre está compreendido, independentemente do quão diferenciada seja a maneira de elucidação e discriminação do domínio de entes (SZ, ss. 6-7). Deste modo, o termo ser estaria se referindo a um marco criterial, no qual estão presentes os itens determinantes dos entes como entes. Mais especificamente, "ser" diz respeito à padrões criteriais aos quais os entes devem estar de acordo para que possam ser entes e entes determinados.' Num marco integrador tais critérios perfazem o que se pode entender por ser, e a construção de uma ontologia em sentido tradicional seria a especificação dos critérios de identidade e individuação de entes que estariam submetidos aos domínios e tipos assim determinados. ${ }^{8}$

Diferentemente, o problema ontológico, entendido como a questão do sentido do ser, consiste no exame da estrutura e natureza da projeção de ser, isto é, a partir de que regras são gerados estes padrões de identificação e individuação ontológica? Se ser é o que permite o encontro com entes como entes determinados, o sentido do ser refere-se à estrutura de constituição e estabilização dos padrões criteriais. Este é o ponto em que surge a inovação proporcionada por Heidegger, pois tal marco de critérios estará referido a um domínio específico de entes: os existentes humanos. O central está na tese de que ser é relativo a uma compreensão de ser, em que o conceito de compreensão é decisivo. Sabemos que a inferência da ontologia fundamental determina que o exame da projeção de ser deve ser buscado numa analítica da existência, e isto quer dizer que todo e qualquer padrão de identificação e individuação ontológica é em si mesmo dotado da qualificação ontológica que é própria do Dasein. Trata-se, portanto, de uma resposta autoadjudicante (Brandom, 1992, p. 47) ao problema de segunda ordem acerca da natureza mesma da diferença nos padrões criteriais de categorialização ontológica. Reconhecendo três domínios de entes: presentidade, disponibilidade e existência, Heidegger sustenta a tese de que todo e qualquer padrão ontológico é de natureza existencial. ${ }^{9}$ Com o peso da projeção de ser colocado no conceito de compreensão, deriva-se um redirecionamento da autoridade criterial. Ou melhor,

7 Essa é a sugestão de Blattner, 1999, p. 5. Estes padrões discriminatórios são qualificadores dos entes, permitindo que sejam tal como são. Evidentemente que não está em jogo a produção da existência dos objetos, mas a sua qualificação determinada. Assim entendido, fica evidente também o sentido da noção de diferença ontológica, a diferença entre os padrões criteriais de identificação e individuaçāo e os objetos assim qualificados, as instâncias de tais "categorias".

- A formulação é de Brandom, 1992, p. 46.

- A hipótese final afirma que o existente humano é essencialmente tempo, temporalidade, e que, portanto, toda e qualquer projeção de ser pela compreensão de ser deverá seguir padrões e regras temporais. Logo, o sentido do ser é o tempo. 
Heidegger está se enfrentando com o privilégio epistêmico na autoridade criterial ontológica.

A análise existencial da compreensão exige que os critérios ontológicos sejam tomados não em sentido intencional ou cognitivo, mas operativo. Ou seja, compreender diz respeito originariamente à habilidade, à capacidade de desempenho e competência. Conseqüentemente, a projeção de ser pela compreensão de ser refere-se não a um relacionamento teórico com entes, mas sim a ações e comportamentos instituídos impessoalmente. A discriminação de tipos ontológicos é estabelecida por padrões de ação responsivas, socialmente normatizadas. ${ }^{10}$ Deste modo, as diferentes categorias ontológicas reconhecidas em Ser e Tempo serão relativas a diferentes padrões de ação recognitivas e responsivas. ${ }^{11}$

Agora torna-se claro de que maneira o Dasein é condição ontológica da verdade enunciativa. Pelo modelo proposto temos o caráter autoadjudicante de toda autoridade criterial ontológica. Isto é, qualquer regionalização efetiva dos entes tem a natureza existencial, querendo dizer que ela depende de uma projeção de ser pela compreensão de ser. Tal projeção está associada diretamente com o caráter prático-social da existência humana, ou seja, os marcos ontológicos de identificação de entes são relativos às normatizações sociais determinantes dos padrões de ação reconhecidos como legítimos em face de determinados entes. A identidade ontológica de um ente é relativa à ação específica com a qual um existente humano comporta-se para com ele. Tal ação pertence a uma classe de ações, a um padrão possivel de ações. Essa classe, por sua vez, é determinada por um outro padrão de ações, a saber, as reações possiveis diante das ações iniciais. Conseqüentemente, podemos falar legitimamente de um padrão de ação simultaneamente recognitivo e responsivo. Responsivo, pois se trata de uma ação em face de outra ação; recognitivo, pois é tal ação que determina e identifica o tipo de ação original. Evidentemente, há um componente normativo aqui, que diz respeito precisamente ao caráter social de tais padrões recognitivos, isto é, refere-se aquilo que um conjunto de pessoas reconhece como sendo uma forma autorizada de reagir em face de uma ação. Nesse caso, a continuidade da análise do tratamento existencial da instanciação ontológica requereria que discutíssemos a socialidade e impessoalidade do Dasein, no sentido de que seriam as condições elementares da projeção ontológica assim entendida. Em resumo, o Dasein é condição ontológica última, pois é dotado da projeção de ser que discrimina os padrões criteriais determinantes das categorias ontológicas.

${ }^{10}$ Este é o lema da escola pragmatista de recepção de Heidegger: constituição é instituição social (Haugeland, 1982), mas que tem sido revisada e criticada atualmente (Haugeland, 1998, p. 4).

1 Entes instrumentais são aqueles determinados por padrões de ação responsiva orientados para finalidades socialmente instituidas e normatizadas. Já o modo ontológico da pura subsistência, o ser objeto dotado de propriedades independentemente de qualquer propósito humano, é relativo ao padrão responsivo do comportamento assertivo. Evidentemente que a categoria da existência representa um grau adicional para a reconstrução ontológica, pois além de ser a fonte de toda diferenciação ontológica, o Dasein também é caracterizado como o elemento último da determinação social da normatização responsiva. Ou seja, deve entrar em jogo aqui os padrões responsivos de reconhecimento mútuo como partícipes de uma comunidade ou grupo social. 
O caráter de verdade do ser refere-se, ao menos no período de Ser e Tempo, à identificação e individuação de entes como entes determinados, à sua condição de estar desvelados na estrutura do algo como algo. Pelos padrões criteriais de qualificação ontológica os entes são colocados nessa condição. Assim, eles podem ser discriminados como correlatos responsivos dos comportamentos humanos, e, eventualmente, de comportamentos assertivos, a partir dos quais temos a verdade em sentido usual.

\section{As condições da verdade}

De acordo com as passagens citadas, a verdade ou falsidade de sentenças descritivas, dos enunciados existenciais e até mesmo das ciências formais, estão em uma relação determinada com a existência humana. Mais exatamente, eles não podem ser ditos verdadeiros ou falsos em um mundo no qual não estiver presente o Dasein. Essa tese deve ser bem entendida.

Inicialmente, não é a verdade efetiva da sentença que é atingida, no sentido de que num mundo sem a existência humana as sentenças confirmadas como verdadeiras se tomariam falsas. A posição sustentada afirma que em tal condição não faz sentido dizer que uma sentença seja verdadeira ou falsa: não podemos afirmar que entes existem nem que não existem; não podemos afirmar que principios lógicos, leis físicas, etc. sejam verdadeiros, nem podemos afirmar que sejam falsos. De outro lado, o termo descobrir, quando se diz que as leis de Newton não eram verdadeiras antes de terem sido descobertas, inclui uma ambigüidade a ser desfeita. Heidegger não pretende que os procedimentos metodológicos de confirmação da verdade determinem a verdade ou falsidade dos enunciados. Se descobrir implica a concepção de um pensamento, ou o reconhecimento da sua verdade, ou a expressão deste pensamento, então é preciso introduzir uma outra distinção central. A tese não está dizendo que é o pensar ou expressar lingüisticamente uma proposição que a faz verdadeira, e que, na ausência de alguém que pense ou se expresse, então não mais haveriam sentenças verdadeiras ou falsas. Nos aproximamos da posição de Heidegger, ao reconhecer que 'descobrir' envolve o sentido de 'asserir' um enunciado ou conteúdo proposicional. Isso é evidente, mas também contém algo de difuso.

Assim, é recomendável diferenciar a condição de um mundo com a presença do Dasein e de um mundo sem tal presença. ${ }^{12}$ Esse é um dado empírico, se considerarmos a espécie humana como portadora da categoria existencial do Dasein. Caso se considere o Dasein enquanto tal, como uma determinação ontológica não apenas humana, então não há porque admitir que o Dasein deva ser um ente necessário. Deste modo, podemos distinguir entre (1) o que pode ser dito, com a presença do Dasein, acerca de objetos em um mundo no qual o Dasein não está presente, e (2) o que pode ser dito, sem a presença do Dasein, acerca de objetos em um mundo no qual o Dasein não está presente. Considerando um tempo pos-

12 Essa apresentação foi proposta por Mulhall, 1996, p. 98-99. 
sível em que a espécie humana não existia ou porventura não mais exista, é possivel enunciar algo sobre os estados de coisas e determinações dos entes possivelmente presentes nestas condições. O tópico geral da descrição seria os estados de coisas presentes em tal mundo, mas devemos diferenciar entre o que pode ser dito sobre este tópico com presença do Dasein e sem a presença do Dasein.

Heidegger não está afirmando que não podemos afimar de entes num mundo sem o Dasein que existem ou não existem, que não podemos afirmar destes entes que estão submetidos a leis ou princípios. Diferentemente, ele sustenta que em um mundo sem o Dasein não se pode enunciar nada. Numa condição em que não está presente o Dasein nenhum enunciado pode ser asserido, nenhum enunciado pode ser posto como verdadeiro nem como falso: não se pode asserir que existam, nem que não existam entes; não se pode asserir que estejam submetidos às leis de Newton, nem que não estejam; não se pode asserir que valem as leis da lógica, nem que não valem. Sem o Dasein não é possível enunciar, logo, é sem sentido pensar uma condição em que estariamos enunciando como seria o mundo então, mas sem que estivessem dadas as condições da enunciabilidade. Em resumo, a tese estabelece a distinção entre o que seria verdadeiro afirmar de objetos, num mundo no qual o Dasein não esteja presente, e a possibilidade de que tais enunciados possam ser proferidos na ausência do Dasein.

Como já mencionamos acima, tal posição pode ser objeto de uma crítica elementar, a saber, que ela consiste apenas em destacar uma trivialidade. Vejamos. Para que seja possivel asserir enunciados (existenciais ou predicativos) são necessárias certas condições empiricas. Essas são as condições da enunciabilidade, que têm sido diferenciadamente investigadas. Entre tais condições está a de que subsista um ente capaz de produzir enunciados, sentenças, proposições, pensamentos, juízos. Não apenas isso, é preciso que esteja presente um ente capaz de asserir tais conteúdos, de agir na direção de pretender que eles sejam verdadeiros. Sem alguém que profira um juízo não há juízo, logo, não há verdade enunciativa, seja de proposições existenciais ou predicativas. As condições da asseribilidade, proferimento e enunciação de uma sentença, proposição ou pensamento são distintas das condições de sua efetiva verdade ou efetiva falsidade. Para que seja enunciável uma sentença são necessárias condições empíricas relativas a quem está asserindo: condições, lingüísticas, biológicas, psíquicas, sociais, etc. Para que ela seja verdadeira, isso depende dos fatos eles mesmos, pois são os entes que tornam a sentença verdadeira ou falsa. Essa última condição diz respeito a algo totalmente indiferente em relação à presença ou ausência de pessoas, do Dasein. Portanto, o núcleo defensável da tese de Heidegger seria uma distinção relevante, mas notoriamente trivial.

No entanto, a tese fenomenológica pretende mais do que indicar a trivialidade. Em particular, a ação de asserir um conteúdo sentencial, notoriamente distinta do conteúdo ele mesmo, será interpretada numa direção que ultrapassa a pretensão de verdade. A interpretação existencial indica que no asserir está a chave para a modificação que possibilita a instituição da categoria de objeto, portanto, a verdade enunciativa. 
A doutrina apontada nas duas passagens citadas deve ser compreendida, portanto, nos seguintes termos: se verdade ou falsidade é uma propriedade possivel dos enunciados - determinada pelos fatos, pelos estados de coisas por eles denotados - então o Dasein é condição de toda verdade. O Dasein não é apenas condição do asserir, da afirmação de que um certo conteúdo proposicional é verdadeiro. A existência é condição da verdade dos conteúdos proposicionais, entendida como a possibilidade de que estejam na altemativa do verdadeiro e do falso. A argumentação procede da seguinte maneira: em primeiro lugar, que um enunciado descritivo seja capaz de mostrar os entes tais como são em si mesmos, essa possibilidade depende necessariamente de pressupostos ontológicos. A possibilidade da verdade depende de uma conceitualização prévia dos entes, depende de uma categorialização determinada. Em segundo lugar, toda e qualquer categorialização de entes é sempre possivel a partir do Dasein, da sua da compreensão de ser. Estes dois passos devem ser analisados a seguir.

\section{1 $A$ verdade enunciativa}

De que modo há uma pressuposição ontológica na possibilidade da verdade enunciativa? Para examinar tal posição é preciso recorrer à doutrina fenomenológica da linguagem, em particular no tocante aos pressupostos ontológicos afirmados no esboço de interpretação existencial da proposição predicativa.

Essa doutrina caracteriza-se pela recusa de uma análise da sentença enunciativa em termos puramente lógico-lingüísticos, na medida em que tal análise partiria do enunciado como um substrato lingüístico ou conceitual. Ao contrário, tratase de interpretá-lo a partir da noção de possibilidade existencial, descrevendo-o no contexto dos modos de ser do existente humano cotidiano. Essa interpretação nos mostra, inicialmente, que a sentença enunciativa tem uma intencionalidade descritiva, isto é, refere-se a algo com a pretensão de exibi-lo em sua efetiva determinação. Porém, essa referencialidade apofântica é uma possibilidade que somente é o caso se o ente ao qual se refere a sentença já esteja previamente acessível e dado. A proposição enunciativa não é primariamente descobridora, caso seja interpretada como uma possibilidade existencial. A possibilidade de um enunciado tomar-se portador da verdade ou da falsidade é condicionada, portanto, pelo acesso prévio ao ente que funciona como sua denotação.

O modo descritivo de acesso aos entes requer uma modificação nas possibilidades existenciais. Inicialmente, os entes nos são primariamente dados como entes instrumentais, determinados por sua inserção em sistemas de relações funcionais, finalizadas em possibilidades instanciadoras de metas e propósitos práticos. Ou seja, os entes tais como nos seriam dados neste acesso pré-predicativo são qualificados como entes disponíveis, como entes dotados de uma remissão finalística relativa a propósitos do existente humano. Conseqüentemente, o objeto possivel de uma descrição sentencial, que deve estar previamente dado para que alguém se lance na possibilidade descritiva, é uma modificação derivativa a partir da categoria da disponibilidade. A apresentação das condições ontológicas da 
verdade enunciativa transita, então, para uma interpretação da modificação da disponibilidade (Zuhandenheit) em subsistência ou presentidade (Vorhandenheit).

Uma relação descritiva com os entes, gerando unidades significativas capazes de dizer como são os seus referentes, independentemente da presença do proferidor e mesmo de seus propósitos, de seus interesses, e da relevância para suas orientações práticas, isto é possível a partir de uma categorialização dos entes em termos de puros objetos, ou então, como portadores potenciais de propriedades e candidatos à membros de relações, com total independência das atribulações humanas. Essa é a ontologia da presentidade: pensar os entes como substratos possiveis de propriedades, que serão ou não o caso com total independência dos propósitos humanos. Uma concepção enunciativa da verdade requer, assim diz a tese de Heidegger, uma compreensão de ser em termos da presentidade.

Retomaremos esse ponto a seguir. Porém, já agora torna-se claro de que maneira o Dasein é condição ontológica da verdade enunciativa. Pelo modelo proposto temos o caráter auto-adjudicante de toda autoridade criterial ontológica. Isto é, qualquer regionalização efetiva dos entes tem a natureza existencial, querendo dizer que ela depende de uma projeção de ser pela compreensão de ser. Tal projeção está associada diretamente com o caráter prático-social da existência humana, ou seja, os marcos ontológicos de identificação de entes são relativos às normatizações sociais determinantes dos padrões de ação reconhecidos como legitimos em face de determinados entes. A identidade ontológica de um ente é relativa à ação específica com a qual um existente humano comporta-se para com ele. Tal ação pertence a uma classe de ações, a um padrão possível de ações. Essa classe, por sua vez, é determinada por um outro padrão de ações, a saber, as reações possíveis diante das ações iniciais. Conseqüentemente, podemos falar legitimamente de um padrão de ação simultaneamente recognitivo e responsivo. Responsivo, pois se trata de uma ação em face de outra ação; recognitivo, pois é tal ação que determina e identifica o tipo de ação original. ${ }^{13}$ Evidentemente, há um componente normativo aqui, que diz respeito precisamente ao caráter social de tais padrões recognitivos, isto é, refere-se aquilo que um conjunto de pessoas reconhece como sendo uma forma autorizada de reagir em face de uma ação. Nesse caso, a continuidade da análise do tratamento existencial da instanciação ontológica requereria que discutíssemos a socialidade e impessoalidade do Dasein, no sentido de que seriam condições elementares da projeção ontológica assim entendida. Em resumo, o Dasein é condição ontológica última, pois é dotado da projeção de ser que discrimina os padrões criteriais determinantes das categorias ontológicas.

A questão posta refere-se, portanto, aos padrões práticos e recognitivos que acabam por gerar o modo de ser da presentidade. Na construção heideggeriana isto envolve uma análise do modo como, a partir da projeção da disponibilidade,

13 Assim, por exemplo, o pregar é a classe de ações que instanciam algo como sendo martelo, mas uma ação conta como sendo do tipo pregar, caso em face dela exista uma outra padrão de ações consideradas apropriadas para tomar as primeiras como sendo do tipo pregar. 
deriva-se o modo de ser da subsistência. Neste ponto chegamos a uma complexidade que facilmente pode se tornar equívoca. A tese é a seguinte: objetos subsistentes, e com propriedades subsistentes independentemente dos propósitos humanos, é o tipo de ente que se instancia a partir do modo enunciativo de comportamento para com eles. $\mathrm{O}$ enunciar, o asserir, é a prática existencial que determina algo como objeto, como ente subsistente. Dito de outra perspectiva, entes subsistentes são aqueles em relação aos quais apenas uma classe de ações é autorizada: 0 asserir. ${ }^{14}$

\subsection{O asserir e a categorialização da pura presentidade}

Torna-se necessário, então, examinar o tratamento fenomenológicoexistencial da proposição enunciativa, pois é somente através dela que se instancia o marco criterial da subsistência, ou seja, a derivação da instrumentalidade em objetualidade subsistente.

A doutrina heideggeriana da proposição enunciativa destaca três momentos constitutivos: apresentação, predicação e comunicação. A forma proposicional elementar refere-se a algo, mostrando-o determinadamente, e com isso permite que seja partilhado com outros uma tal exibição predicativa. Em geral, a literatura a esse respeito tem destacado $o$ aparente componente encobridor que 0 aspecto lingüístico e proposicional possuiria, na medida em que estando registrado em uma linguagem o descobrimento ôntico permitiria que outros enunciassem sem estar na relação originária de descobrimento. ${ }^{15}$ Porém, concedendo uma importância reconstrutiva especial para o momento comunicante-compartilhador (mitteilend) do fenômeno da proposição enunciativa, estaremos em condições de encontrar a chave para a modificação da disponibilidade em subsistência.

O elemento comunicante da proposição enunciativa nos remete à dimensão de autorização e responsabilidade que caracteriza o asserir como um instrumento específico. Quando asserimos uma proposição estamos fazendo uma permissão, uma autorização a outros: a de reasserir nosso enunciado. $O$ aspecto lingüísticocomunicativo do enunciado diz respeito ao componente autorizativo que contém, isto é, de permitir que outros também possam asserir nossa alegação, isto é, reasserir. Associado ao componente predicativo, essa autorização estende-se para além da reasserção, na medida em que autoriza também a produção de novas asserções, isto é, de todas aquelas que estão presentes no inferir outras proposições a partir da que fora inicialmente afirmada. Neste sentido, asserir significa autorizar outros à reasserção e à inferência, trata-se de uma licença para retirar todas as conclusões permitidas pela discursividade conceitual dos predicados. De

14 Estaremos nos baseando integralmente na doutrina da asserção oferecida por Robert Brandom, em seus trabalhos de 1976, 1983 e 1992. Stanley Cavell apresentou uma tese similar em seu conhecido artigo de 1958 (Must we mean what we say?), segundo a qual o emprego usual de um termo pode ser visto como uma autorização para realizar inferências, para extrair conclusões (1964, p. 84). Merker, por exemplo, identifica aqui o componente,gnóstico-plotiniano do pensamento de Heidegger (1988, ss. 88-130). 
outro lado, a produção de uma asserção contém também a dimensão de uma responsabilização. Quem afirma uma alegação compromete-se com a exigência de justificá-la. Deste modo, qualquer um que faça uma reasserção e extraia conclusões a partir de tal alegação inicial submete-se ao jogo de responsabilizações justificacionais, incluindo até mesmo o lance extremo da desobrigação de justificar a alegação, precisamente por transferi-la para o proferidor inicial (Brandom, 1983, p. 640 e ss.).

Em resumo, abordagem heideggeriana permite uma reconstrução da asserção como uma atividade prática, incluindo as práticas responsivas de autorização e do jogo justificaticional. Fazer uma asserção, afirmar uma proposição enunciativa, consiste em autorizar a prática inferencial e responsabilizar-se pela prática justificacional, permitindo inclusive a isenção de justificação da parte daqueles que assumem 0 direito à reasserção.

Comportar-se diante de algo fazendo asserções, e tudo o que está envolvido na dimensão de responsabilidade e autorização, é tratar algo como algo subsistente, como mera presentidade. Para que seja possivel a categorialização dos entes em termos de objetos portadores de propriedades é necessário que esteja desenvolvido a possibilidade assertiva, ou seja, a produção das ações normatizadas que caracterizam 0 asserir. Tais ações remontam-se a uma outra classe de ações, a saber, aquelas que reconhecem como tal o asserir, seja em termos de reasserção inferencial, seja em termos de isenção da própria justificação. Podemos dizer que o padrão de ações reativos e responsivos que determinam algo como objeto dotado de propriedades autônomas é exatamente a classe de ações sociais denominadas de asserção. ${ }^{16}$

O sentido de autonomia ontológica das propriedades de um objeto diz respeito precisamente à independência de tais determinações em relação aos propósitos práticos humanos. Vista como um tipo de recontextualização, a modificação da disponibilidade em presentidade permite uma interpretação mais ou menos exigente, de acordo com a aceitação de uma possibilidade extrema, que Heidegger chama de pura subsistência ou pura presentidade (Brandom, 1992, p. 61). A adequação própria de uma asserção refere-se aquilo que constitui a objetividade das propriedades dos entes subsistentes: que a justificabilidade da asserção é independente de qualquer propósito prático humano. Deste modo, por meio do comportamento assertivo, e de todo o complexo de práticas socialmente normatizadas que abrange (sobretudo nas suas dimensões autorizativas e responsabilizadoras), é que ocorre pela primeira vez uma regionalização dos entes em termos de presentidade. A derivação do modo da disponibilidade para o da subsistência é possível como derivação da interpretação em enunciado:

Sem o Dasein, entendido como o modo ontológico de ser de um ente fundamentalmente operacional e social, que se projeta em possibilidades e com isso desvela modos de ser, não seria possível qualquer regionalização ontológica. Em

Essa interpretação original foi desenvolvida por Brandom (1992). 
particular, não aconteceria aquela regionalização que possibilita o encontro com entes como objetos portadores de propriedades autônomas e independentes. Esse é o sentido em que a verdade enunciativa pressupõe a ontologia da subsistência, e como tal pressupõe o Dasein. Na medida em que esse desvelamento de ser é chamado de verdade ontológica, e na medida em que a projeção ser é chamada de verdade originária, torna-se manifesto o sentido próprio de afirmar que a verdade originária é condição da verdade enunciativa. E essa é a formulação mais própria para a tese da dependência de toda verdade em relação ao Dasein.

\section{Restos de teologia}

Podemos resumir a análise empreendida em três pontos: (1) a categorialização da objetualidade é possível pelo padrão recognitivo responsivo que é a asserção; (2) tal padrão é normatizado socialmente, isto é, é possibilitado pelo pertencer a uma comunidade social que reage adequadamente e reconhece o modo assertivo de comportamento; (3) essa pertinência é a determinação ontológica do existente humano, enquanto social e responsável pela projeção prática de ser. Tal reconstrução permite, portanto, uma resposta à objeção de ceticismo e relativismo. $O$ que podemos notar é que a doutrina heideggeriana implica uma mudança no modo de conceber a verdade e as condições de possibilidade da verdade de um enunciado, mais especificamente, ela implica uma discussão dos pressupostos filosóficos que estão na afirmação de conteúdos proposicionais independentes, em relação aos quais faria sentido perguntar por sua verdade ou falsidade independentemente da sua asserção. Heidegger não está propondo a relatividade de toda verdade efetiva dos enunciados, mas sim o reconhecimento da pressuposição ontológica que está na base da pretensão de dizer o mundo tal como ele é independentemente dos propósitos do existente humano. ${ }^{17}$

Não reconhecer a determinação existencial da verdade enunciativa, isto é, não reconhecer a sua instituição pelo modo de ser do Dasein, é precisamente a atitude filosófica que possibilita falar de uma condição em que seriam verdadeiros ou falsos os enunciados sem a presença do Dasein. O que faz de tal presunção um sem sentido é que ela ignora as condições últimas que possibilitam a relação enunciativa para com entes enquanto objetos.

Essa condição foi descrita por Heidegger, ao referir-se ao seu oposto simétrico: a ausência de toda instituição ontológica seria como a noite absoluta. Numa condição em que não está presente nenhuma categorialização ontológica, não faz sentido dizer que são verdadeiros ou falsos os enunciados que poderão ser mostrados como verdadeiros ou falsos. Simplesmente não estão dados os pressupostos ontológicos que permitem falar da possibilidade da verdade e da falsidade. Colocar-se em tal posição, isto é, propor a possibilidade de representar enunciativa-

17 Imediatamente após as afirmações inicialmente citadas Heidegger diz precisamente isso: que tal relativização da verdade ao Dasein não diminui em nada o seu efetivamente ser verdadeiro (ver também GA 27, § 14). 
mente sem o Dasein, somente seria possível a partir da aceitação de um ponto de vista privilegiado: a visão do mundo sob o aspecto da eternidade. Creio que é este o sentido próprio em que devemos tomar a afirmação que Heidegger faz ao final do § 44, quando nos diz que a aceitação de verdades eternas representa os restos de teologia cristã na problemática filosófica.

Mais do que um ateísmo metodológico está presente aqui. No entanto, não estamos lidando com um relativismo cético ingenuamente concedido. A conhecida afirmação de que a investigação filosófica é ateísmo (GA 20, ss. 109-10) não tem, além disso, o sentido de uma proposição existencial negativa, na qual se nega a existência de um ente divino, mas sim a recusa de uma perspectiva em que são abstraídas as pressuposições ontológicas que fazem possível a verdade enunciativa. A aceitação da noite absoluta, para usar a metáfora, significa, conseqüentemente, a inserção no modelo finitista e existencial de tratamento dos problemas filosóficos, entre eles os da teoria do conhecimento e da filosofia da lógica. A dependência de toda verdade em relação ao Dasein não implica a diminuição do seu ser efetivamente verdadeiro, mas o reconhecimento das condições que conferem sentido às noções de independência e autonomia da verdade enunciativa.

A metáfora da noite absoluta diz respeito à possibilidade que se abre quando reconhecemos à necessária pressuposição de um desvelamento de ser para toda e qualquer relação para com entes, inclusive aquela na qual se instaura a possibilidade de descobri-los em suas propriedades autônomas e independentes do existente humano. É certo que Heidegger promove uma interpretação ontológicoexistencial dos temas centrais da metafísica da luz, ao qualificar o Dasein como dotado de um lumen naturale (Strube, 1996, 109). A retomada da metafísica da luz pretende indicar, no uso metafórico do contraste noite-dia, a dimensão ontológica que condiciona toda a verdade e falsidade dos pensamentos, exigindo assim a retomada do problema do ser. A verdade originária e a compreensão de ser, que tornam possivel toda verdade enunciativa, concretizam a iluminação que se apropria da existência humana. Essa luz não é incondicionada, e na sua ausência temos a noite absoluta.

Curiosamente, essa possibilidade é uma das maneiras como Heidegger tematizou o problema do não ser: o nada. Abstraindo de antigos preconceitos, e também daquilo que enseja tais preconceitos na própria obra de Heidegger, a noção de não-ser pode ser entendida em pelo menos duas acepções básicas. Inicialmente, pela significação própria do conceito de ser, que não pode ser tomado como equivalente ao conceito de ente ou objeto. Esse é o sentido mais próximo do conceito de diferença ontológica, ou seja, aquilo quie perfaz o conjunto de critérios de individuação e identificação de entes não pode ser tomado ele mesmo como sendo um objeto ou ente. Ser e nada se identificam, pois o a priori ontológico não é um ente. Porém, devemos avançar para outra acepção dessa noção, quando se afirma que ser e nada se copertencem, pois em toda projeção de ser haveria também ocultamento, retraimento de ser.

A projeção de ser é também o retraimento de ser: desvelamento é também ocultamento de ser. Evidentemente que essa não é uma mísera contradição. O seu 
verdadeiro significado pertence ao plano de um pensamento sobre as condições da verdade e do descobrimento de entes. Podemos nos aproximar de seu significado trazendo a problemática na qual se insere, e que Heidegger manifestara ao final de seu escrito "O que é metafísica?" Lá ele dizia que a questão fundamental da metafísica era: por que existe afinal ente e não antes nada ${ }^{18}$ Tal pergunta recebe de Heidegger uma acepção muito distinta daquela que dominou a ontologia ocidental desde Leibniz, em que se estaria na busca de uma razão para que algo exista em vez de não existir. ${ }^{19}$ Em vez disso, Heidegger lê uma tal indagação na direção que nos permite compreender o conceito de não-ser na acepção agora relevante. Numa entrevista por ocasião de seu octogésimo aniversário ele afirmou:

"Mas esta questão tem para mim um sentido inteiramente diferente. A idéia metafísica que se faz habitualmente do que está sendo perguntado nessa questão significa: no final das contas, por que o ente é e não antes o nada? Quer dizer: onde está a causa ou o fundamento para que o ente exista e não o nada? Eu, de minha parte, pergunto: por que o ente existe e não sobretudo o nada? Por que o ente tem prioridade, por que o nada não é pensado como idêntico ao ser? Quer dizer: por que o esquecimento do ser reina e de onde ele vem? Trata-se pois de uma questão inteiramente diferente da questão metafísica. Ou seja, eu pergunto: o que é a metafísica? Eu não formulo uma questão metafisica, mas sim a questão sobre a essência da metafísica." (GA 16, s. 708)

A preponderância dos entes quer dizer o retraimento da consideração sobre suas condições de possibilidade, o que, no caso da relação descritiva, alcança seu patamar último. A história da filosofia é entendida como história da metafísica, pois representania a tematização e também a perda da conceitualização própria do âmbito das condições do relacionamento com os entes. A projeção de ser possibilita que os entes imponham-se em seu poder, diante do qual a relação descritiva origina-se como uma das formas possivveis de sustentação (GA 27, § 42). Decaídos e submetidos pela supremacia dos entes, é possível que se desdobre a relação descritiva, ou seja, é possível a descrição dos objetos em suas propriedades independentes. Uma tal absorção é acompanhada com a desconsideração dos horizontes ontológicos implícitos que a permitem. Não-ser significa aqui, então, a preponderância ofuscante da relação com os entes, que atinge o extremo no retraimento da tematização apropriada das condições ontológicas de tal relação. Em todo descobrimento de ser há retraimento de ser, isto é, ser pode ser pensado como idêntico ao não-ser também nessa acepção. Ao contránio, quando se reconhece a condicionalidade ao Dasein de todo desvelamento de ser, portanto, de todo descobrimento de entes, então podemos pensar uma condição de ausência do Dasein como a ausência de qualquer possibilidade de verdade: a "noite absoluta". 20

${ }_{18}$ Was ist Metaphysik, 1965 (1929), s. 42.

19 Já foi apontado na literatura que o pensamento de Heidegger sobre o não-ser afasta-se da abordagem metafisica ocidental, tendo recebido fortes influências de motivos do pensamento oriental, em particular do Tao. Ver Reinhard May (1989, p. 22-34) e Graham Parkes (1987).

${ }^{20}$ Esse é precisamente o ponto de inserção da temática do tempo, pois a especial temporalidade do saber também deve poder ser mostrada em sua condicionalidade relativamente ao tempo originánio do Dasein. 


\section{Referências bibliográficas}

APEL, Karl-Otto. Wittgenstein und Heidegger: kritische Wiederholung und Ergänzung eines Vergleichs. In: MACGUINNESS, B. (Hg) "Der Löwe spricht ... und wir können ihn nicht verstehen". Frankfurt am Main, Suhrkamp, 1991. ss. 27-68.

BRANDOM, Robert. Truth and assertibility. The Journal of Philosophy (73): 6, 1976, p. 137-149. Asserting. Noûs 17, 1983. pp. 637-50.

. Heideggers Categories in Being and Time. In: DREYFUS \& HALL, H. Heidegger: A Critical Reader. Oxford, Blackwell, 1992. p. 45-64.

BLATTNER, William. Heidegger's Temporal Idealism. New York, Cambridge University Press, 1999.

CAVELL, Stanley. Must we mean what we say? In: Chappell, V. C. Ordinary Language. New York, Dover Publications, 1964.

DAHLSTROM, Daniel O. Das logische Vorurteil. Wien, Passagen Verlag, 1994.

DREYFUS, Hubert Coping with Things in thenselves: Heidegger's Robust Realism. In: http:// socrates.berkeley.edu/ frege/dreyfus/Short_Realism_Bielefeld.html.

GABRIEL, Gottfried. La 'Logica' di Hermann Lotze e la nozione di validità. Revista di Filosofia (81): 3, 1990, p. 457-468.

HAUGELAND, John. Heidegger on Being a Person. Noûs, 1982. p. 15-26.

HAUGELAND, John. Having Thought. Cambridge, Mass., Harvard University Press, 1998.

HEIDEGGER, Martin. Was ist Metaphysik. 9 Auf. Frankfurt am Main, Vittorio Klostermann, 1965.

- Die Grundprobleme der Phänomenologie. 2. ed. In: Gesamtausgabe 24 (Sommersemester 1927). Frankfurt am Main, Vittorio Klostermann, 1976.

— Logik. Die Frage nach der Wahrheit. In: Gesamtausgabe 21 (Wintersemester 1925/26). Frankfurt am Main, Vittorio Klostermann, 1976.

-.... Metaphysische Anfangsgründe der Logik. In: Gesamtausgabe 26 (Sommersemester 1928). Frankfurt am Main, Vittorio Klostermann, 1978.

- Frühe Schriften. In: Gesamtausgabe 1. Frankfurt am Main, Vittorio Klostermann, 1978.

Sein und Zeit. 17. Auf. Tübingen, Max Niemeyer Verlag, 1986.

- Prolegomena zur Geschichte des Zeitbegriffs 2 ed. In: Gesamtausgabe 20 (Sommersemester

1925). Frankfurt am Main: Vittorio Klostermann, 1988.

- Einleitung in die Philosophie. In: Gesamtausgabe 27 (Wintersemester 1928/29). Frankfurt am

Main, Vittorio Klostermann, 1996

- Reden und andere Zeugnisse eines Lebensweges. In: Gesamtausgabe 16. Frankfurt am Main, Vittorio Klostermann, 2000.

MAY, Reinhard. Heidegger's Hidden Sources. London \& New York, Routledge, 1996.

MERKER, B. Selbsttäuschung und Selbsterkenntnis. Zu Heideggers Transformation der Phänomenologie Husserls. Frankfurt am Main, Suhrkamp, 1988.

MOHANTY, J. N. Heidegger on Logic. In: Macann, C. Heidegger. Critical Assessments (Vol. IV). London/New York, Routledge, 1992. p. 93-119.

MULHALL, Stephen. Heidegger and 'Being and Time'. London, Routledge, 1996 .

PARK, Graham. Heidegger and Asian Thought. Honolulu, University of Hawaii Press, 1987.

PHILIPSE, Herman. Heidegger's Philosophy of Being. A Critical Interpretation. Princenton, Princenton University Press, 1999.

OKRENT, Mark. Heidegger's Pragmatism. Understanding, Being, and the Critique of Metaphysics. Ithaca, Comell University Press, 1988.

. Why the Mind Isn't a Program (But Some Digital Computer Might Have a Mind) EJAP/1996. Spring.

RYLE, Gilbert (1929) Heidegger's Sein und Zeit. In: Murray, Michael Heidegger and Modem Philosophy. New Haven and London: Yale University Press, 1978. p. 53-64.

STRUBE, Claudius. Die existenzial-ontologische Bestimmung des lumen naturale. Heidegger Studien 12, 1996, ss. 109-119. 